\title{
SUBSÍDIO PARA A HISTÓRIA DA ENFERMAGEM NO ESTADO DO PARANÁ
}

\author{
Wanda de Aguiar Horta*
}

\begin{tabular}{l|l|}
\cline { 2 - 2 } & $\mathrm{RBEn} / 08$ \\
\hline
\end{tabular}

HORTA, W.A. - Subsídio para a história da Enfermagem no Estado do Paraná. Rev. Bras. Enf.; RJ, $28: 60-64,1975$.

\section{INTRODUÇÃO}

Relendo o artigo "A Enfermagem no Estado do Paraná" de Terezinha B.G. de Azevedo, publicado na Revista Brasileira de Enfermagem de fevereiro de 1965, senti imperiosa necessidade de contribuir com alguns subsídios para que um dia se possa completar os claros ainda existentes, sobre a história da enfermagem do Brasil contemporâneo

Para melhor compreensão do que irei expor, peço vênia para me reportar ao passado, revendo os fatos conexos que antecederam a minha participação na enfermagem do Paraná.

\section{ENCONTRO COM A ENFERMAGEM NÃO PROFISSIONAL}

Nascida em Belém do Pará, não recordo de ter sofrido, durante a infância, qualquer influência no sentido de optar por esta ou aquela profissão. Em 1937, por problema de saúde de meu pai, mudamos para o Paraná.

Em Ponta Grossa fiz ginásio e pré- médico, as duas outras áreas oferecidas, pré-jurídico e pré-engenharia, decididamente não me atraíam.

O Brasil havia declarado guerra ao Eixo, estávamos em plena mobilização militar e preparo do povo para possíveis ataques aéreos. A Cruz Vermelha Brasileira, filial de Ponta Grossa, abriu curso para Voluntários Socorristas, no qual me inscrevi. O curso era à noite, essencialmente teórico e dado por médicos. A pedido de um professor, preparei uma aula sobre esterilização, tendo por bibliografia um livro ,por ele indicado, de Otto Bier. Estudei, preparei a aula, que afinal não cheguei a dar, mas, em compensação, aprendi muito e me interessei vivamente pela microbiologia.

Em caravana da Cruz Vermelha, participando da programação de um feriado nacional, fui a Curitiba, onde desfilei como enfermeira, num uniforme improvisado, sentindo-me como se tudo fosse verdadeiro. Ao regressar, entusiasmada (estava com 16 anos) ao saber que a

* Professor Adjunto da Escola de Enfermagem da Universidade de São Paulo. 
HORTA, W.A. - Subsídio para a história da Enfermagem no Estado do Paraná. Rev. Bras. Enf.; RJ, 28 : 60-64, 1975.

Força Expedicionária Brasileira teria um corpo de enfermeiras, pedi autorização a meus pais e telegrafei ao Ministro da Guerra, oferecendo-me para integrar a FEB. Não recebi, obviamente em razão da pouca idade, resposta a este telegrama.

Em 1944, mudamos para Curitiba. Desejava ingressar na Faculdade de Medicina, mas, por motivos financeiros e por não ter ainda a idade requerida para o ingresso, procurei trabalhar e estudar para o vestibular.

Recebi convite de D. Rosalina Niepce da Silva, diretora do Posto de Puericultura da Legião Brasileira de Assistência, da Praça Carlos Gomes, para trabalhar em atividades de enfermagem. Adquiri, então, os rudimentos da profissão com uma antiga funcionári do posto e com o médico Pediatra, Dr. Waldemar Monastier. Aplicada medicação por todas as vias, fazia provas tuberculínicas, observava as crianças e fui adquirindo, sob a orientação de Dr. Monastier, muitas noções de patologia e pediatria. Durante as férias de minha colega, que no período da tarde trabalhava no consultório daquele pediatra, fui substituí-la, sendo solicitada pelos clientes de Dr. Monastier para ministrar injeções a domicílio em crianças e em adultos. Foi então que pude aplicar, com segurança, muitos dos conhecimentos de microbiologia de Otto Bier. Ainda que empiricamente, pude também fazer um pouco de enfermagem de Saúde Pública, tendo procurado transmitir à clientela improvisada as noções de assepsia médica e cirúrgica aprendidas para a aula frustrada já referida.

Um dos episódios mais marcantes nesta minha atividade inicial em enfermagem prática, ocorreu quando precisei aplicar a domicílio, $500 \mathrm{ml}$ de solução fisiológica, por via subcutânea, numa criança que estivera pela manhã no Posto, passando muito mal, com desi- dratação. A tarde, tomei o bonde para a Água Verde, o endereço era vago, no meio dos campos então lá existentes; depois de perguntar de casa em casa foi com dificuldade que encontrei a residência, mas ao chegar lá a criança havia morrido. Meu abatimento foi muito grande, chocada com o primeiro contato com a morte, ainda mais pelo fato de ser uma criança.

No início de 1945, D. Rosinha N. Silva deu-me para preencher um formulário para uma bolsa de estudos para estudar na Escola de Enfermagem de São Paulo, anexa à Faculdade de Medicina da Universidade de São Paulo. Foi desta maneira que tive conhecimento de que havia escolas onde se estudava enfermagem e onde, como matérias curriculares, teria entre outras, aquelas mesmas microbiologia, anatomia, fisiologia com as quais me havia entusiasmado ao primeiro contato já referido.

A bolsa de estudos à qual, afinal, me canditatei foi dada ao Paraná pelo Serviço Especial de Saúde Pública (SESP), órgão recém-criado pelo Governo Federal em colaboração com o governo dos Estados Unidos da América. Esta bolsa era oferecida sem vínculo de compromisso para trabalhar naquele serviço.

A resposta formal à minha solicitação - quando já me desesperava com a demora - vim afinal a tê-la por gentileza de Dr. Waldemar Monastier que, viajando para o Rio de Janeiro, atendeu meu pedido de informar-se sobre a concessão da bolsa no SESP.

Fiquei ciente então da obtenção da bolsa e até que o curso já havia começado em São Paulo.

Naquela época a escola se instalava no já famoso Hospital das Clínicas da Faculdade de Medicina da USP, onde iniciei o curso regular de enfermagem, em companhia de colegas que se tornaram imediatamente companheiras e amigas. 
HORTA, W.A. - Subsídio para a história da Enfermagem no Estado do Paraná. Rev. Bras. Enf.; RJ, 28 : 60-64, 1975.

\section{ENCONTRO COM A ENFERMAGEM PROFISSIONAL}

O curso de enfermagem feito entre julho de 194.5 a novembro de 1948 foi, para mim, contínua fonte de satisfação e aprendizagem. Na escola conheci Alice Michaud, paranaense, e também bolsista do SESP, visitadora sanitária que havia ido estudar enfermagem por indicação de Dr. Bichat Rodrigues, Secretário de Saúde do Paraná, Ficamos amigas e embora de classes diferentes nos formamos na mesma data, novembro de 1948.

\section{PARÁ (SERVIÇO ESPECIAL DE SAÚDE PÚBLICA) INICIAÇÃO PROFISSIONAL}

De fins de novembro de 1948 a dezembro de 1949 trabalhei em Santarém, no SESP. Este serviço, por sua filosofia de trabalho, deu-me uma perspectiva da enfermagem que se desenvolveu e que conservo até hoje, isto é, que a enfermagem é um todo indivisível, não se fragmenta em compartimentos estanques, tal como o homem objeto de sua atenção. No SESP havia trabalho de equipe - médicos, engenheiros, enfermeiros todos interessados no bem comum: a saúde da população; éramos colegas de trabalho, nos reuníamos, discutíamos e decidíamos quais as medidas a tomar.

O Hospital era também Centro de Saúde, o que hoje se chama Unidade médico-Sanitária. Os clientes eram acompanhados no Centro e depois no Hospital, caso fossem internados, sem solução de continuidade no seu atendimento. A assistência à população era completa, bem diferente daquela aprendida na Escola, em Enfermagem de Saúde Pública. Trabalhávamos com a população e não para ela. Ali pude ter experiências de aprendizagem tanto no Hospital como no Centro de Saúde e em docência. Fui assistente da Diretora dos Cursos de Visitadores Sanitários e de Auxiliares Hospitalares, lecionando dj- versas disciplinas com estágio no campo clínico. Por motivo de doença na família regressei ao Paraná em dezembro de 1949.

\section{PARANA - BASES PARA O DESENVOLVIMENTO DE SUA ENFERMAGEM PROFISSIONAL}

Logo ao chegar em Curitiba procurei a Secretaria de Saúde, oferecendo meus serviços como enfermeira de saúde pública. Enquanto aguardava o emprego, ingressei na Faculdade de Filosofia para fazer o curso de História Natural.

Fui contratada pela Secretaria de Saúde para trabalhar no Sanatório Médico Cirúrgico do Portão, hospital de tuberculose. Apresentei-me ao Diretor Dr. João Luiz Bettega e iniciei meu exercício neste nosocômio, onde fiquei 4 anos, de 1950 a 1954.

Fiquei sabendo, muitos anos depois, que a solicitação expressa de Dr. Bettega de uma enfermeira para a direção de enfermagem do Sanatório do Portão, sob sua chefia clínica prendia-se à sua própria formação profissional, aluno que fora do Prof. Odair Pedroso, que julgava indispensável a presença da enfermeira para a administração e desenvolvimento de uma estrutura hospitalar completa.

Durante os quatro anos neste Sanatório recebi sempre todo o apoio de seu Diretor; qualquer pedido era providenciado imediatamente. Isto me incentivou e permitiu que desse ao hospital as condições mínimas para que funcionasse e a infra-estrutura necessária ao desenvolvimento de atividades clínicas e de pesquisa programadas para o sanatório. O desvelo da direção do Sanatório do Portão por sua chefia de enfermagem inclui o que merece sem dúvida destaque particular, o fornecimento de recursos para participação em congressos, não só de Enfermagem como de Tuberculose, Higiene, e outros. 
HORTA, W.A. - Subsídio para a história da Enfermagem no Estado do Paraná. Rev. Bras. Enf.; RJ, $28: 60-64,1975$.

Aí foi onde teve seqüência meu aprendizado de enfermagem, principalmente no que se refere à administração hospitalar. No meu currículo de graduação em enfermagem não havia a disciplina Administração em Enfermagem. Não é pois de estranhar que, colocada em fase de problemas administrativos de um hospital com cerca de 200 leitos, incluindo cirurgia pulmonar, isso tenha sido por vezes penoso, por conflitante com a minha formação, orientada para a enfermagem de cabeceira.

Organizei e provi pessoalmente, de maneira empírica, educação em serviço para as atendentes, rotinas, reestrututuração do Centro Cirúrgico, Centro de Material, plano de assisteência para o pós-operatório imediato, escalas de serviço e trabalho, enfim, o mínimo de base administrativa para o desenvolvimento técnico do hospital.

Além destes aspectos mais de caráter administrativo, não me descuidei da educação dos pacientes e da participação em pesquisas com o corpo clínico, resultando daí meu primeiro trabalho de investigação em enfermagem apresentado em 1951, em Belo Horizonte, durante o V Congresso Nacional de Tuberculose.

Cometi, acredito, muitos erros, mas o saldo final pareceu-me positivo.

Alice Michaud, ao voltar para Curitiba, recém-formada, foi requisitada pelo Diretor do Hospital da Cruz Vermelha para dirigir e organizar o Serviço de Enfermagem daquele nosocômio. Extremamente dedicada, entregou-se totalmente à tarefa, com prejuízo de sua própria saúde. Foi aí que a encontrei ao regressar ao Paraná. Nesta ocasião houve uma tentativa para a criação de uma escola de enfermagem no referido hospital, por solicitação do Diretor da Cruz Vermelha do Paraná. O Ministério da Educação enviou Da. Cecília M. D. Sanioto e Miss Ella Hasenjaeger para es- tudar a viabilidade do projeto, mas esta comissão não encontrou as condições mínimas necessária para iniciar um curso de enfermagem, recomendando, se fosse de interesse, a instalação de curso de Auxiliar de Enfermagem, no que também concordava Alice Michaud.

Junto com Alice Michaud empreendemos uma série de atividades que hoje, sei, foram as sementes da enfermagem atual do Paraná. A partir de 1950 promovemos as Semanas de Enfermagem - palestras nas rádios Paranaense e Guairacá e em colégios, igrejas, artigos para jornais ou notícias relacionadas a Enfermagem e publicidade em lojas do centro comercial.

Organizamos cursos para atendentes, patrocinado pela Secretaria de Saúde, obrigando a freqüência de todas as atendentes do Sanatório. Destes cursos saíram algumas das futuras líderes da enfermagem no Paraná. Empenhei-me pessoalmente para obter três bolsas de estudo para alunas dos cursos de Visitadoras Sanitárias da Secretaria de Saúde, onde ministrei aulas de Ética, estudarem na Escola de Enfermagem da USP. Só uma delas ficou nessa escola; as outras duas foram para o Rio de Janeiro: uma formou-se na Escola Luiza de Marillac e a outra não terminou o estudo iniciado.

Consegui, ainda, que duas atendentes do Sanatório fizessem o Curso de Auxiliar de Enfermagem na Escola de Auxiliares de Enfermagem São José, em São Paulo.

Na Faculdade, como estudante, fiz intensa propaganda de minha profissão, seja com colegas ou professores; quando, no penúltimo ano, iniciei trabalhos de pesquisa em Genética Humana com o Professor Newton Freire-Maia, foi justamente o interesse pela Enfermagem que me levou ao estudo desta área da genética.

Por duas vezes a Dra. Haydée Guanais Dourado esteve no Paraná, durante este 
HORTA, W.A. - Subsídio para a história da Enfermagem no Estado do Paraná. Rev.

Bras. Enf.; RJ, 28 : 60-64, 1975.

quatriênio; ela era Diretora de Enfermagem do Serviço Nacional de Tuberculose. Na primeira vez conseguiu reunir cinco enfermeiras para um jantar de congraçamento, quando foi criada a Secção do Paraná, da Associação Brasileira de Enfermagem (ABen). Descobrimos que havia em Curitiba mais três enfermeiras, duas na Maternidade Victor do Amaral e uma enfermeira de Saúde Pública do Ministério da Saúde, adida à Secretaria de Saúde. A ABEn do $\mathrm{Pa}$ raná teve vida efêmera, pois, logo depois as duas enfermeiras da Maternidade deixaram a cidade. Da segunda vez Dr. ${ }^{a}$ Haydée, Alice e eu estivemos com o Professor Flávio Suplicy de Lacerda, então Reitor da Universidade do Paraná, para tratar da criação da Escola de Enfermagem; fizemos parte da Comissãa, apresentamos planos e currículo, mas infelizmente até hoje o nosso projeto não se tornou realidade.

Pouco antes de deixar o Paraná participei também da elaboração do currículo e da orientação de alguns docentes da Escola de Enfermagem Madre Leonie, que se encontrava em fase de organização pelas irmãs da Congregação de São José.

Em 1953, quando deixava o Paraná, providenciei, com a ajuda de Dr. Bettega, convênio com o Serviço Nacional de Tuberculose, de maneira que lá ficassem duas enfermeiras bem preparadas, com conhecimento do campo; estas trabalharam comigo alguns meses, a fim de que o Serviço de Enfermagem do Sanatório não sofresse solução de continuidade. Alice Michaud retornara à Secretaria de Saúde assumindo a Chefia do Serviço de Enfermagem.

Em dezembro de 1953 casei-me e pedi demissão do Serviço Público do Estado do Paraná, mas lá ficou Alice Michaud dando, com outras colegas, continuidade à luta pela enfermagem profissional.

Terminando esta exposição dos fatos transcorridos entre 1950 e 1953 peço a permissão para deixar neste trabalho a minha sincera homenagem a esta enfermeira paranaense que, com humildade e perseverança, soube, no seu Estado, lutar pela afirmação e melhor conceito de nossa profissão.

\section{SEMEANDO}

Eramos duas

a trabalhar, e lutar.

Como a gralha azul semeamos pinheiros, sem pensar em glória, poder, ou vantagens.

Acreditávamos

em nosso trabalho

e na enfermagem.

Para outras terras um dia, a vida me "levou. Você ficou, trabalhando, sofrendo, semeando e crendo.

Os pinheiros semeados cresceram, frutificaram e venceram. Você não parou, continuou lutando, trabalhando, semeando, sem pensar em glória, poder ou vantagem; somente por acreditar na enfermagem! 